\title{
Novel Use of Surgical Calliper in Excision of Cutaneous Melanomas
}

\author{
Mohamed Maher*, Pradeep Janardhanan and Shivram Singh \\ Department of Plastic Surgery, Queen Elizabeth Hospital, UK
}

Submission: October 02, 2017; Published: October 26, 2017

*Corresponding author: Mohamed Maher, Department of Plastic Surgery, Queen Elizabeth Hospital, Mendelsohn Way, B15 2TH, Birmingham, UK, Email: mohamed.maher@doctors.org.uk

\begin{abstract}
Surgery remains the mainstay treatment modality for primary cutaneous melanoma. The surgical resection margin is predetermined prior to excision depending on the Breslow thickness in millimeters of the original melanoma. We present the use of the compass to precisely circumscribe the excision margin, as well as using it to identify the apices of the fusiform excision. This aids in direct closure without standing cones/dog ears
\end{abstract}

\section{Introduction}

The definitive surgical management of cutaneous melanoma involves excision of the lesion with a variable margin. Current guidelines dictate that excisional biopsy of suspected melanoma should include the entirety of the tumor with a $2 \mathrm{~mm}$ lateral margin of normal tissue and cuff of fat inferiorly. After histopathological staging of the specimen, the melanoma biopsy scar is excised with a margin ranging between $0.5 \mathrm{~mm}$ to $3.0 \mathrm{~cm}$, depending on the Below thickness [1]. Broadly, the aims of surgical excision of cutaneous lesions are two-fold: curative (or reduction of disease burden), and aesthetically acceptable reconstruction. Primary closure of a circular defect will produce unfavorable 'dog-earing' - cutaneous standing cones - at the ends of the closed wound. Dog-earing can be minimized with basic techniques.

The fusiform ellipse, otherwise known as the surgical ellipse, is an approach for excision of cutaneous lesions that can minimize dog-earing. It is produced by the overlap of two ellipses, and has two vertices [2]. As a general rule the length of the fusiform ellipse should be three times the width, with $30^{\circ}$ angle at the tips of the ellipse. Closure of the ellipse will result in a linear scar. In common surgical practice the margins of excision are measured and constructed free hand. Experienced surgeons often estimate the length of ellipse. If under-estimated, this can result in dog-earing, and an aesthetically unfavorable result. In this paper we describe the use of callipers/compass in measuring and constructing the circumferential excision margin and the extent of the ellipse (Figures $1 \& 2$ ).

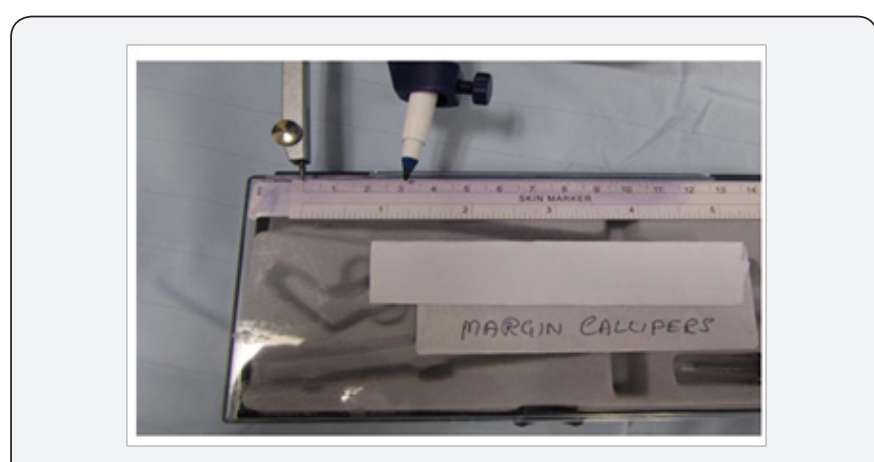

Figure 1: Calipers being adjusted to predetermined margins.

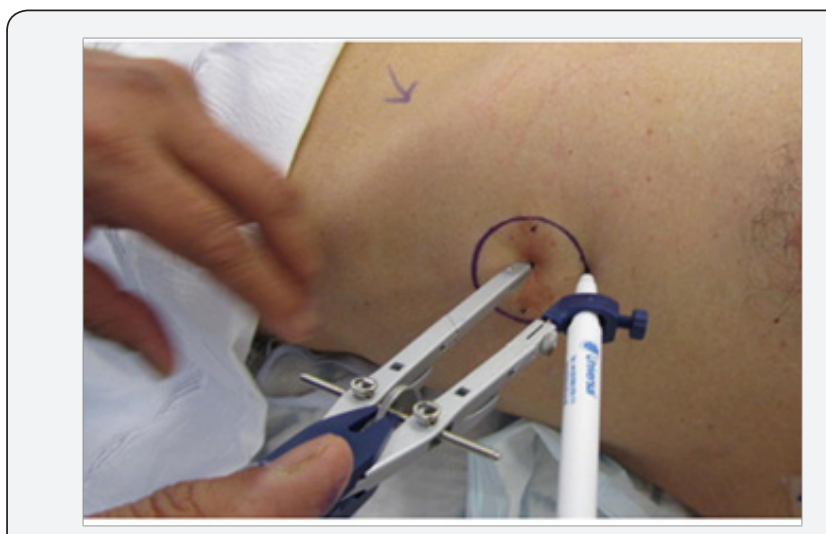

Figure 2: WLE margin being perfectly and accurately marked out. 


\section{Method}

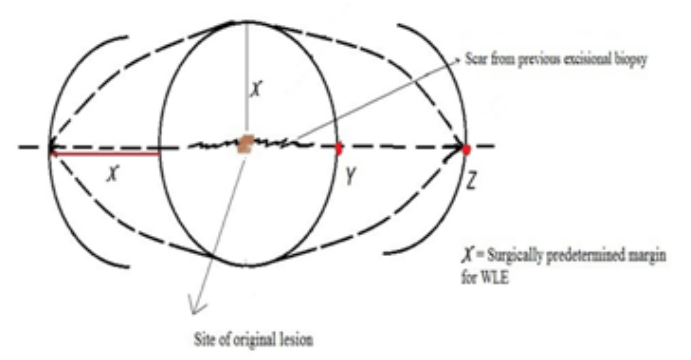

Figure 3: diagrammatic representation of WLE ellipse formation.

Figure 3: diagrammatic representation of WLE ellipse formation.

The wide local excision (WLE) is performed after the diagnosis has been confirmed and the Below thickness determined. The dimensions of the original lesion excised should be noted and extrapolated on the excision biopsy scar. The surgically predetermined margins should be from this point (Figure 3) as opposed to being measured from each end of the scar. The compass is set to the predetermined margins and centered over the middle of the scar and the WLE margin is drawn. A pinch test is then done to determine the lines of maximum extensibility, to allow for the scar to be placed in the relaxed skin tension lines (RSTL's) [3] for an aesthetic result. The compass is then placed at each end of the WLE marking where it bisects the RSTL (point Y). An arc is drawn at from each point with same predetermined margin. This delineates the apices of the ellipse (point Z) and this where the arc bisects the RSTL. The resection is down to the next surgical plane, and closure of the wound is in layers.

\section{Benefits of Caliper Use}

In routine practice within plastic surgery both the WLE margins and ellipse are constructed freehand. There are theoretical drawbacks of freehand WLE construction. Firstly, inaccurate construction of the circumferential margin increases the likelihood of inadequate resection, and thus of cancer recurrence, if the margins are under-estimated, whereas overestimation of the margin worsens overall cosmesis. Secondly, in regard to ellipse formation, the freehand formations of a skewed or uneven ellipsewill ultimately affect the linearity of the final scar. The use of a caliper enables the construction of accurate and adequate circumferential WLE margins and the ellipse to facilitate closure (Figure 4). Thus there are tangible advantages of using a caliper in melanoma surgery. To conclude, we recommend the use of calliper in excision of cutaneous malignancies and lesions requiring construction of a surgical ellipse.

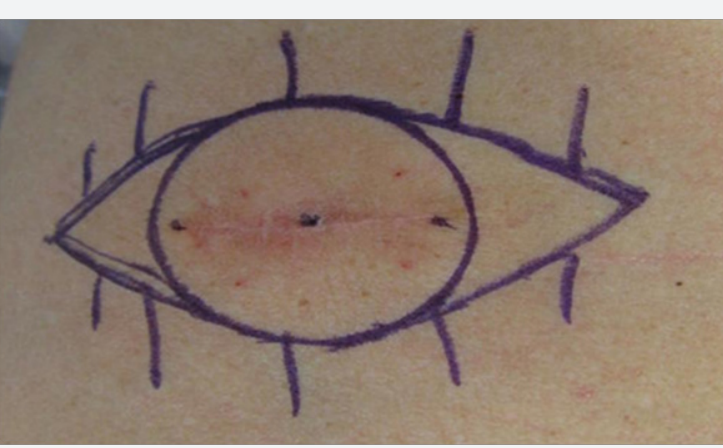

Figure 4: Accurate final marking of elliptical excision.

\section{References}

1. Marsden JR, Newton Bishop JA, Burrows L, Cook M, Corrie PG, et al. (2010) Revised UK guidelines for the management of cutaneous melanoma 2010. British Journal of Dermatology (163): 238-256.

2. Tilleman T, Tilleman MM, Neumann MHA (2013) The paradigm of surgical ellipse dimensions: are the length-to-width ratio of 3 to 4 and a vertex angle of $30^{\circ}$ correct? Surgical Scienc 4: 236-240.

3. Leitenberger JJ, Isenhath SN, Swanson NA, Lee KK (2015) Surgery of the skin: revision of surgical scars $3^{\text {rd }}$ edn, USA.

\section{Your next submission with Juniper Publishers will reach you the below assets}

- Quality Editorial service

- Swift Peer Review

- Reprints availability

- E-prints Service

- Manuscript Podcast for convenient understanding

- Global attainment for your research

- Manuscript accessibility in different formats

( Pdf, E-pub, Full Text, Audio)

- Unceasing customer service

Track the below URL for one-step submission https://juniperpublishers.com/online-submission.php 